\title{
Self expandable stents for relief of venous baffle obstruction after the Mustard operation
}

\author{
S C Brown, B Eyskens, L Mertens, L Stockx, M Dumoulin, M Gewillig
}

\begin{abstract}
Objective-Obstruction of the venous pathways after Mustard repair for transposition of the great arteries is associated with an increased risk of arrhythmia and sudden death. The purpose of this study was to assess the effectiveness of the largest (tracheal $22 \times 40 \mathrm{~mm}$ ) Wallstents in treating baffle obstructions.

Design-Retrospective analysis of patients with stented venous pathways.

Subjects-Eleven patients with baffle obstruction after Mustard repair for transposition of the great arteries.

Interventions-Stenoses were dilated with an 18 or $20 \mathrm{~mm}$ balloon. However, recoil was noticed in 11 patients: immediately $(n=7)$ or on repeat angiography $(n=4)$. Eighteen stents were implanted (mean (SD)) 18 (3.3) years postoperatively. After dilatation a tracheal Wallstent $(11.5 \mathrm{~F})$ was deployed.
\end{abstract}

Main outcome measures-Relief of obstruction, haemodynamic improvement.

Results-In the inferior vena cava, 10 stents were deployed in seven baffle obstructions with an increase in diameter from $9.8(2.4) \mathrm{mm}$ to $16.5(1.4) \mathrm{mm}(\mathrm{p}<0.01)$ and a mean (SD) pressure gradient decrease from $5.1(3.6) \mathrm{mm} \mathrm{Hg}$ to $1.4(2.0) \mathrm{mm} \mathrm{Hg}$; in the superior vena cava, eight stents were implanted increasing the diameter from $9.1(3.7) \mathrm{mm}$ to $15.6(3.8) \mathrm{mm}(\mathrm{p}<0.001)$ with a decrease in mean pressure gradient from $5.1(2.7) \mathrm{mm} \mathrm{Hg}$ to 1.9 (1.5) $\mathrm{mm} \mathrm{Hg}$. No complications were experienced during implantation. No anticoagulation was prescribed. During follow up $(1.7$ (0.6) years; range, 0.9-2.6) no problems were noted; five patients were re-catheterised without change in measurements. There was no evidence of peal formation in any of the stents.

Paediatric Cardiology University Hospital

Gasthuisberg, Leuven,

Belgium

S G Brown

B Eyskens

L Mertens

M Dumoulin

M Gewillig

Radiology

L Stockx

Correspondence to: Professor Dr M Gewillig, Paediatric Cardiology,

University Hospitals Leuven, B 3000, Leuven, Belgium.

Accepted for publication 15 July 1997

Introduction of the Mustard and Senning procedures greatly improved the survival of children with transposition of the great arteries (TGA). ${ }^{1}$ The first Mustard operation was performed in $1963 .^{23}$ Late complications after this procedure are numerous ${ }^{4-7}$; the most promi- nent are obstruction of the superior and inferior vena cavae (SVC, IVC), pulmonary venous obstruction, baffle leaks, tricuspid regurgitation, right ventricular dysfunction, and arrhythmias. ${ }^{8}$ The incidence of venous pathway obstruction varies between $0 \%$ and $40 \%{ }^{4}{ }^{79}$ The reasons for baffle obstruction are manifold, but surgical technique ${ }^{4}$ and the use of Dacron ${ }^{510}$ as material for the baffle seem to be important causes. Treatment consists of surgery ${ }^{10}$ requiring cardiopulmonary bypass, or balloon dilatation, ${ }^{11}{ }^{12}$ which often results in temporary relief and the need for repeat dilatations. Recently, balloon expandable intravascular stents ${ }^{13} 14$ have been increasingly used for the treatment of both malignant and nonmalignant obstructions of the systemic venous system. Ward et $a l^{13}$ postulated that stenting may become the procedure of choice for the relief of systemic venous and venous baffle obstruction in the paediatric population. Here we present our experience with the use of self expandable intravascular stents for systemic venous baffle obstruction in patients who had previously undergone the Mustard procedure.

\section{Methods}

PATIENTS

During the period October 1971 to September 1981, 42 of our patients with TGA had undergone a Mustard repair. Age at operation ranged from 0.3 to 9.7 years (mean (SD) 2.5 (2.1)). Of these, 29 were simple TGA and 13 complex TGA. In total there were nine $(21 \%)$ early deaths. Thirty two survivors were followed up at the outpatient clinic and screened for obstruction of the venous system a mean of 19.6 (3.3) years later (range 10-24.8). There were 27 men and 15 women. Nineteen (45\%) patients had obstruction of the venous baffle system and two (5\%) had pulmonary venous obstruction.

All patients were evaluated by clinical assessement, chest radiography, and echocardiography. In those in whom obstruction was suspected, cardiac catheterisation was done. Obstruction was considered to be present if a patient was symptomatic or if a mean pressure difference of more than $3 \mathrm{~mm} \mathrm{Hg}$ was measured between the caval vein and the venous atrium, in the presence of an angiographic narrowing of the venous pathway of more than $40 \%$, or the presence of a dilated azygos vein with run off.

\section{PROCEDURE}

Procedures were done under general anaesthesia. Venous access was gained from the femoral venous route in all patients. Routine 

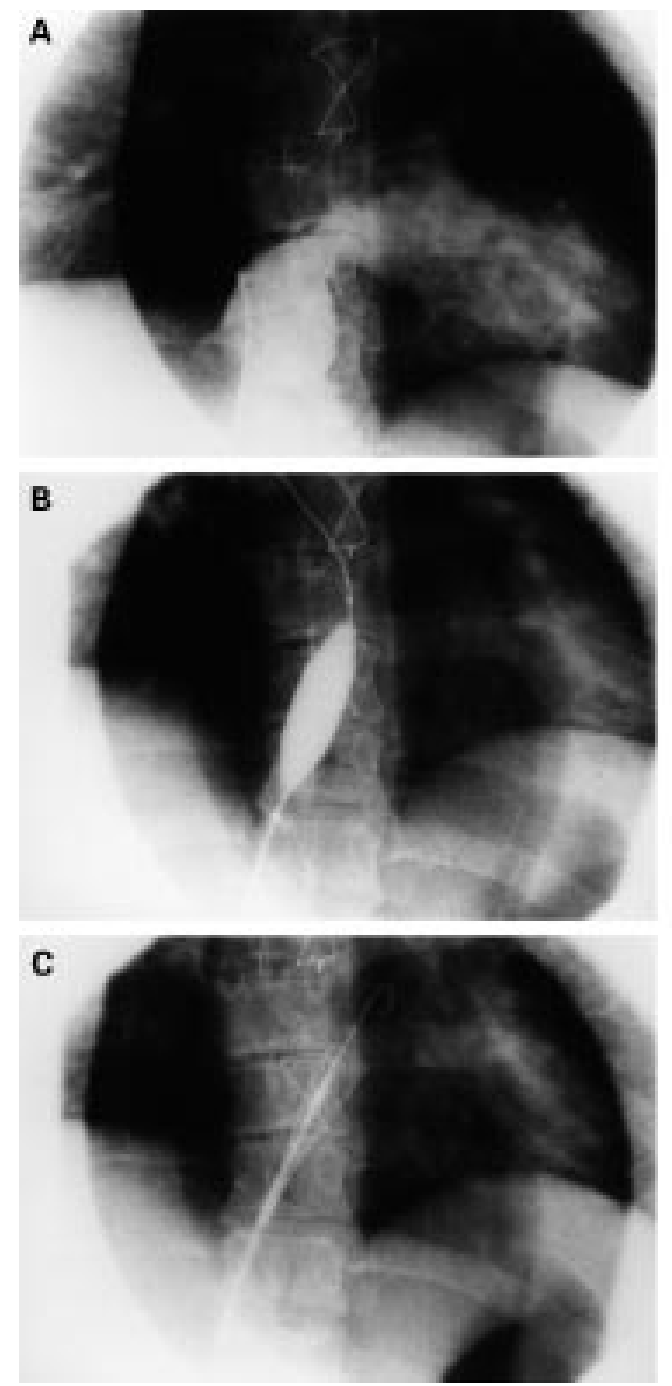

catheterisation data and measurements were obtained and pressure gradients repeated after stent implantation. Angiography was done in standard biplane positions before and after the procedure.

Standard catheters and techniques were used. Details of the technique for stent implantation have been published elswhere. ${ }^{15-20}$ In brief, the site of obstruction was crossed and a 0.035 inch guidewire (Amplatz extra stiff) was left in situ. All obstructions were predilated with either an $18 \mathrm{~mm}$ or $20 \mathrm{~mm}$ standard balloon. The stent was then introduced and deployed.

Large $(22 \times 40 \mathrm{~mm})$ endotracheal Wallstents (Schneider, Buläch, Switzerland) were used in all patients. The reason for choosing this particular stent was because of its large size and ease of deployment. This particular stent is a self expandable stent folded on a shaft and covered by a stiff outer sleeve. The real diameter of the mounted stent is $11.5 \mathrm{~F}$ gauge.

The device can be opened by withdrawal of this outer sleeve and, if not released, folded back by advancing the sleeve and can then be repositioned. The Wallstent has an inherent radial expansion force because of its construction, which allows it to open and maintain pat-
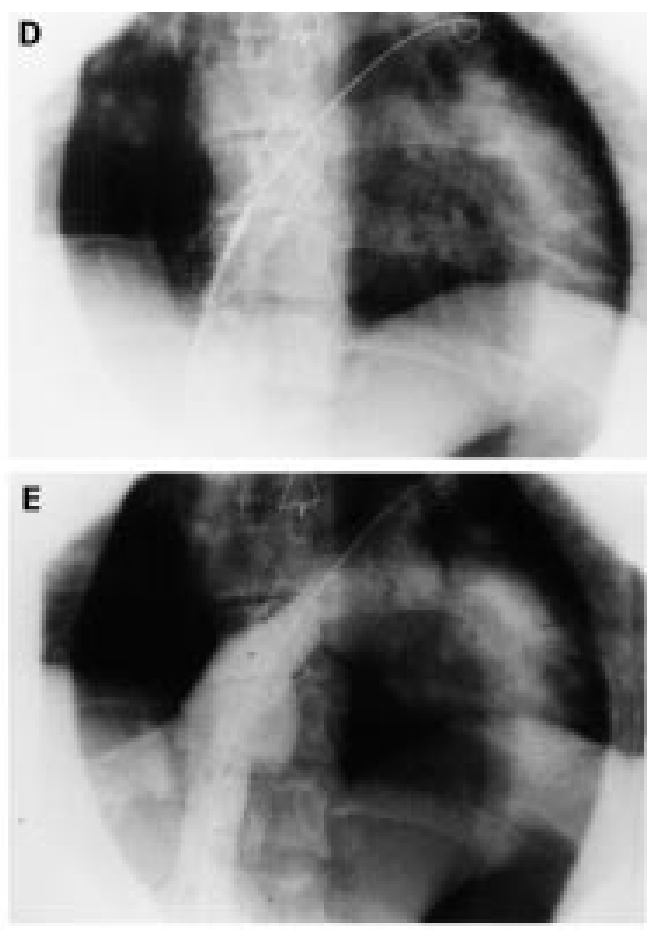

Figure 1 (A) Angiogram of IVC injection. There was a $6 \mathrm{~mm} \mathrm{Hg}$ gradient across the pathway; note the prestenotic dilatation of the IVC. (B) Balloon dilatation with $18 \mathrm{~mm}$ balloon; there was complete disappearance of the waist, but repeat pull back showed no change of gradient across the pathway. (C) Partial deployment of the Wallstent: the outer pathway. (C) Partial deployment of the Wallstent: the outer
sleeve is withdrawn for two thirds of the total length of the stent. At this point the stent is pulled into the ideal position, and the outer sleeve is further withdrawn until full

expansion of the stent. (D) Full expansion of the stent; the shaft is carefully withdrawn. (E) Control angiogram showing good positioning of the stent; there was a residual gradient of $1 \mathrm{~mm} \mathrm{Hg}$.

ency once released. As we gained more experience and confidence with use of this device, we placed the leading edge of the stent somewhat distal to the obstruction. This distal part of the stent was then allowed to open and the device slowly pulled into position and then released (fig 1). This was applied after some of the stents (3 VCI pathways), because of our inexperience at the initial stage, were expanded either too proximally or distally necessitating placement of a second stent. Using this technique, we could easily control positioning and avoid the stent protruding into the venous atrium.

Procedures were done under direct fluoroscopy. No form of anticoagulation was routinely given either before or after the implantation of the stents, except if arterial cannulation was done (eight patients), in which case a single dose of heparin $50 \mathrm{U} / \mathrm{kg}$ (maximum $2500 \mathrm{U}$ ) was given. Antibiotic prophylaxis consisted of the administration of cephalozin $(50 \mathrm{mg} / \mathrm{kg}$ one hour before the procedure to a maximum of $2 \mathrm{~g}$, repeated once six hours later).

FOLLOW UP

Patients were followed up 1.7 (0.6) years (range 0.9-2.6) after the procedure using the same protocol as described for the initial 
Table 1 Patient and demographic data

\begin{tabular}{lllllll}
\hline Patient & $\begin{array}{l}\text { Weight } \\
(\mathrm{kg})\end{array}$ & Sex & $\begin{array}{l}\text { Presurgical } \\
\text { diagnosis }\end{array}$ & $\begin{array}{l}\text { Surgery for baffle } \\
\text { obstruction }\end{array}$ & $\begin{array}{l}\text { Age at } \\
\text { stenting }\end{array}$ & Stent position \\
\hline 1 & 41.6 & F & TGA + VSD & Once (PLE) & 17 & IVC,SVC \\
2 & 73.8 & M & TGA + VSD & & 20 & SVC \\
3 & 54.5 & F & TGA & & 16 & IVC, SVC \\
4 & 79.6 & F & TGA & Once & 22 & SVC \\
5 & 81.6 & M & TGA & Twice & 21 & SVC \\
6 & 43.0 & F & TGA & & 28 & SVC \\
7 & 66.9 & M & TGA + PS & 17 & IVC \\
8 & 68.3 & F & TGA & & 24 & IVC \\
$9^{\star}$ & 45.7 & F & TGA + VSD & & 16 & IVC \\
10 & 77.4 & M & TGA & & 25 & IVC, SVC \\
11 & 61.0 & F & TGA + VSD & & 26 & IVC, SVC \\
\hline
\end{tabular}

*This patient had grade IV histologically confirmed pulmonary hypertension; a palliative Mustard operation was done.

TGA, transposition of the great arteries; VSD, ventricular septal defect; PS, pulmonary stenosis; PLE, protein losing enteropathy.

evaluation. Magnetic resonance imaging was also done where possible $(n=8)$ as part of the follow up procedure.

STATISTICAL ANALYSIS AND MEASUREMENTS

The internal diameter of the narrowest segment before and after stent implantation was measured from the cine-angiographic images and scanned into a deskscanner using a computer software package (Adobe Fotoshop, Adobe Systems, USA; Medvision, Evergreen Technologies, USA). Where possible a calibrated guidewire (Lunderquist vessel measure guide, Cook) was used or otherwise measurements were compared with known standard catheter sizes. The values obtained before and after stent implantation were analysed using the paired Student's $t$ test. Values of $\mathrm{p}<0.05$ were considered significant. Standard statistical methods were used to derive the mean, median, and standard deviation.

\section{Results}

Treatment for the 19 patients diagnosed with obstruction of the venous pathways was as follows: three had surgery only; four underwent surgery followed by primary dilatation or stenting, or both $(\mathrm{n}=2$, residual angiographic narrowing); three only balloon angioplasty; two underwent balloon dilatation and were later stented because of residual narrowing of the baffle; and seven were stented because of immediate elastic recoil after pre-dilatation.

Wallstents were implanted in 11 patients. A total of 18 stents were implanted during 13 procedures, eight in SVC and 10 in the IVC. Table 1 summarises patient characteristics and data. The stents were implanted 18 (3.3) years postoperatively (range 12.2-22.2). In the stented group only one baffle was constructed from pericardium, all others were in Dacron. The stents were placed 4.8 years in patient 1 and 2.8 years in patient 6 after repeat surgery for baffle obstruction and in patient 518.4 years after repeat surgery for a leaking baffle. In the IVC group diameter increased from $9.8(2.4) \mathrm{mm}$ (range 6.7-12.4) to $16.5(1.4) \mathrm{mm}$ (range 15.3-18.7; p < 0.01); the mean pressure gradient decreased from $5.1(2.7) \mathrm{mm} \mathrm{Hg}$ (range 3.0-11.0) to 1.9 (1.5) $\mathrm{mm} \mathrm{Hg}$ (range $0-4.0 ; \mathrm{p}<0.01$ ). An additional stent was placed in the IVC of two patients because of distal or proximal deploy- ment during the learning curve phase and one later for invagination of tissue.

In the SVC group diameter increased from $9.1(3.7) \mathrm{mm}$ (range 4.3-14.8) to 15.6 (3.8) $\mathrm{mm}$ (range 9.8-21.3; p $<0.001$ ) and the mean pressure gradient decreased from $5.1(3.6) \mathrm{mm} \mathrm{Hg}$ (range 2.0-13.0) to 1.4 (2.0) mm Hg (range 0-5.0; p 0.05).

COMPLICATIONS AND FOLLOW UP

There were no complications during stent implantation. Specifically, no incidents of bleeding or perforation were experienced during implantation. In one patient a stent was deployed too close to the mitral valve after release, but pulled into position using an endomyocardial biopsy forceps. One patient with a palliative Mustard became more cyanosed after relief of obstruction: the improvement in venous return was such that after stent placement saturations decreased from $88 \%$ to $83 \%$.

Five patients were re-catheterised a mean of $1.2(0.8)$ years after stent implantation. None of the stents showed signs of peal formation, fracture or restenosis. There was no difference in mean pressure or gradient at follow up catheterisation compared with immediate poststent values. In patient 3 a second stent was placed in the IVC because of an invagination of tissue at the venous atrium-IVC baffle junction. Patient 10 had a His bundle ablation done and pacemaker inserted subsequently for recurrent atrial flutter (present before stenting). The protein losing enteropathy with which patient 1 presented disappeared completely and has not resurfaced during follow up.

At follow up seven patients were in NYHA class I and four in NYHA class II. One patient became pregnant and subsequently gave birth to a healthy baby girl.

Follow up investigations showed all baffles to be patent. It was interesting to note that transthoracic echocardiographic imaging showed the stents clearly after implantation (much better than the original pathways).

\section{Discussion}

Although the Mustard operation has largely been abandoned, ${ }^{7}$ there are still many patients who have undergone the procedure and may present with problems of venous baffle obstruction. The experience with stenting has been increasing and a number of reports ${ }^{14-25}$ in the medical literature also indicated the effectiveness of stents to relieve this type of venous obstruction. Few have however looked at this group in particular and in most only stenting of the superior caval vein was reported in patients who had undergone the Mustard operation.

Venous baffle obstruction in patients who have undergone the Mustard procedure is a serious problem; it has been identified as a risk factor for sudden death and arrhythmia. ${ }^{26}$ Bearing this in mind, obstruction should be actively looked for and treated. Stenting has satisfactorily relieved obstruction of both the 
inferior and superior limbs of the venous pathways in our group of patients as reflected by the significant increase in baffle diameter after placement of stents.

Because a Wallstent cannot be dilated more than its nominal diameter, care should be taken to select an appropriate size. We used the largest available stent at the time $(22 \mathrm{~mm})$. This particular type of stent has some advantages: it is longer than most other stents available, easily positioned (can be partially deployed and "pulled" into the exact position/repositioned), and needs only one balloon for predilatation (whereas in other stents one balloon for positioning and another for final expansion is often neccessary).

Haemodynamic improvement was experienced in most of our patients. In the short and medium term no significant effects were noted on the occurrence of arrhythmias. The stents remained patent without the use of anticoagulation. No recurrence of obstruction was noticed. There was no evidence of peal formation. Clinical symptoms (for example, protein losing enteropathy) also improved and patients reported improved exercise tolerance, although this may be subjective. One patient with a palliative Mustard became more cyanotic after successful relief of the inferior caval vein obstruction.

\section{STUDY LIMITATIONS}

Several limitations of this study are recognised. No assessment of the efficacy of surgical repair compared with stenting has been made, but although a recent report indicated surgery ${ }^{12}$ to be effective, others ${ }^{24}$ mention recurrent obstruction after surgery. This was also seen in our limited series. Furthermore, stenting saves the patient from going on bypass, as all forms of surgical repair of baffle obstruction neccessitate bypass. Longer term follow up will be necessary to assess the continued efficacy and patency of stents. This study did not attempt to discover if this technique with self expandable stents is better than the balloon expandable stents.

In conclusion, stents are effective in relieving baffle obstruction in patients who have undergone the Mustard procedure. The ease of deployment and characteristics of the Wallstent make it ideal for the treatment of venous baffle obstruction. The procedure is safe and offers at least a short to medium term solution with significant haemodynamic improvement. More studies need to be done concerning the long term patency and efficacy of the stents, but medium term follow up are promising. Anticoagulation does not seem neccessary. We suggest stenting as the treatment of choice for patients with venous baffle subobstruction after Mustard repair.

1 Turley K, Verrier ED, Merrick SH, Ebert PA. The Mustard procedure in infants (less than 100 days of age). 7 Thorac Cardiovasc Surg 1988;96:849-53.

2 Mustard WT. Successful two-stage correction of transposition of the great vessels. Surgery 1964;55:469-72.
3 Trusler GA. The Mustard procedure: a commentary. Ann Thorac Surg 1987;43:570-1.

4 Stewart S, Alexson C, Manning J. Late results of the Mustard procedure in transposition of the great vessels. Ann Thorac Surg 1986;42:419-24.

5 Ashraf MH, Cotroneo J, DiMarco D, Subramanian S. Fate of long-term survivors of Mustard procedure (inflow repair) for simple and complex transposition of the great arteries. Ann Thorac Surg 1986;42:385-9.

6 Warnes CA, Somerville J. Transposition of the great arteries: late results in adolescents and adults after the Mustard procedure. Br Heart f 1987;58:148-55.

7 Helbing WA, Hansen B, Ottenkamp J, Rohmer J, Chin JGJ, Brom AG, et al. Longterm results of atrial correction for transposition of the great arteries. Comparison of Mustard and Senning operations. F Thorac Cardiovasc Surg 1994; 108:363-72.

8 Myridakis DJ, Ehlers, Engle MA. Late follow-up after venous switch operation (Mustard procedure) for simple and comæplex transposition of the great arteries. Am $\mathcal{f}$ Cardiol 1994;74:1030-6.

9 Stark J, Silove ED, Taylor JFN, Graham GR. Obstruction to systemic venous return following the Mustard operation for transposition of the great arteries. 7 Thorac Cardiovasc Surg 1974;68:742-9.

10 Kron IL, Rheuban KS, Joob AW, Jedeiken R, Mentzer RM, Carpenter MA, et al. Baffle obstruction following the Mustard operation: cause and treatment. Ann Thorac Surg 1985;39:112-5

11 Kirk CR, Gibbs JL, Wilkinson JL, Wilson N, Dickinson DF, Qureshi SA. Protein-losing enteropathy caused by baffle obstruction after Mustard's operation. Br Heart 7 1988:59. 69-72.

12 Wisselink W, Money SR, Becker MO, Rice KL, Ramee SR, White CJ, et al. Comparison of operative reconstruction and percutaneous balloon dilatation for central venous obstruction. Am f Surg 1993;166:200-5.

13 Ward CJB, Mullins CE, Nihill MR, Grifka RG, Wesley Vick III. Use of intravascular stents in systemic venous and systemic venous baffle obstructions. Short term follow-up results. Circulation 1995;91:2948-54.

14 Schranz D, Michel-Behnke I, Schmid F, Oelert H. Gradual angioplasty and stent implantation to treat complete superior vena cava occlusion. Cathet Cardiovasc Diagn 1996;38: 87-90.

15 Rocchini AP, Meliones JN, Beekman RH, Moorehead C, London $M$. Use of balloon-expandable stents to treat experimental peripheral pulmonary artery and superior vena caval stenosis: preliminary experience. Pediatr Cardiol 1992;13:92-6

16 O'Laughlin MP, Slack MC, Grifka RG, Perry SB, Lock JE, Mullins C. Implantation and intermediate-term follow-up of stents in congenital heart disease. Circulation 1993;88: 605-14.

17 Redington AN, Weil J, Somerville J. Self expanding stents in congenital heart disease. Br Heart f 1994;72:378-83.

18 Dyet JF, Nicholson AA, Cook AM. The use of the Wallstent endovascular prosthesis in the treatment of malignant endovascular prosthesis in the treatment of malignant
obstruction of the superior vena cava. Clin Radiol 1993;48: 381-5.

19 Shuping Ge S, Shiota T, Rice MJ, Hellenbrand WM, Sahn DJ. Transesophageal ultrasound imaging during stent mplantation to relieve superior vena cava-to-intra-atrial baffle obstruction after Mustard repair of transposition of the great arteries. Circulation 1995;91:2679-80.

20 Watkinson AF, Hansell DM. Expandable Wallstent for the treatment of obstruction of the superior vena cava. Thorax 1993;48:915-20.

21 Hatai Y, Nykanen DG, Wilæßliams WG, Freedom RM, Benson L N. The clinical impact of percutaneous balloon expandable endovascular stents in the management of early postoperative vascular obstruction. Cardiology in the Young postoperative

22 Hosking MCK, Murdison KA, Duncan WJ. Transcatheter stent implantation for recurrent pulmonary venous pathway obstruction after the Mustard procedure. Br Heart $\mathcal{F}$ 1994;72:85-8

23 Bu'Lock FA, Tometzki AJ, Kitchener DJ, Arnold R, Peart I, Walsh KP, et al. Intracardiac stents solve a baffling problem [abstract]. Cardiology in the Young 1996;6(suppl):S4.

24 Abdulhamed JM, Yousef SA, Ali Khan MA, Mullins C. Balloon dilatation of complete obstruction of the superior vena cava after Mustard operation for transposition of the great arteries. Br Heart f 1994;72:482-5.

25 Chatelain P, Meier B, Friedli B. Stenting of superior and inferior vena cava for symptomatic narrowing after repeated atrial surgery for D-transposition of the great vessels. Br Heart 7 1991;66:466-8.

26 Gewillig M, Cullen S, Mertens B. Risk factors for arrhythmia and death after Mustard operation for simple transposition of the great arteries. Circulation 1991; 84(suppl):III187-92.

27 Kaemmerer HA, Theissen P, Schirg E, Kaulitz R, Schicha $\mathrm{H}$, Kallfelz H. Postoperative complications after the Mustard operation for complete transposition-a qualitative evaluation with magnetic resonance imaging. Cardiology in the Young 1996;6:62-8. 